\section{Quality indicators: the rationale behind their use in NHS dentistry}

\author{
I. Mills ${ }^{1}$ and P. Batchelor ${ }^{2}$
}
IN BRIEF
- Improving the quality of healthcare has been a key priority for successive governments.
- The absence of any incentive or reward for improvement in quality in the 2006 dental contract has been widely criticised but will now be assessed as part of the new contract pilots.
- This paper aims to provide an overview on how quality in healthcare may be defined and how it can be measured.

This paper explores the concept of quality as applied to healthcare and its subsequent application to dentistry. The assessment of quality arose from the manufacturing industry and is viewed as a cornerstone of current Government thinking. The difficulties in defining and therefore in measuring are examined and, in particular, the tensions between quantifying quality at a population level and at an individual level. The findings of the application of quality measures to primary medical care are reviewed, especially those that are linked to financial reimbursement of care providers and the implications for any future dental agenda discussed.

\section{INTRODUCTION}

The delivery of quality has been suggested as being key to the long-term success and viability of any business, whether in the manufacturing, service or healthcare sectors. The work of Deming and Juran ${ }^{1}$ has had a profound influence on the understanding and appreciation of the importance of quality from their involvement in the Japanese car manufacturing industry in the 1950s. They recognised that as quality improved 'costs go down and productivity goes up' but were also aware that 'cutting costs without improvement of quality is futile'.

Improving the quality of health services has been a key priority for successive governments, although some critics may feel that in recent years target driven efficiency has been the real focus within the NHS. ${ }^{2}$ Developing the quality agenda was part of the Labour government's ten-year modernisation plan published in $1997 .^{3}$ The aim was to create a: "modern and dependable

\footnotetext{
'NIHR Academic Clinical Fellow in General Dental Practice and Honorary Lecturer, Peninsula Dental School, University of Plymouth; $2^{2 *}$ Course Director, Dental Leadership \& Management Programme, Faculty of General Dental Practice (UK) and Consultant in Dental Public Health, Thames Valley Public Health Network

${ }^{*}$ Correspondence to: Dr lan Mills

Email:millsy@eclipse.co.uk
}

\section{Refereed Pape}

Accepted 7 April 2011

DOI: $10.1038 /$ sj.bdj.2011.521

${ }^{\bullet}$ British Dental Journal 2011; 211: 11-15 health service fit for the twenty-first century. A national health service which offers people prompt high quality treatment and care when and where they need it. ${ }^{3}$

The White Paper was published to address issues affecting the NHS at that time. These included unacceptable waiting times, variable quality of care and an excessively bureaucratic system. Various policies were subsequently introduced to address these problems, ${ }^{4-6}$ with a significant injection of funding to support their introduction and implementation. The plan included structural reorganisation to allow local commissioning, integration of services, partnership working, patient involvement and development of a 'quality agenda'.

Clinical governance has become an important aspect of quality assurance and was first introduced in 1997 with the publication of the Government white paper A first class service. ${ }^{7}$ This was partly in response to the Bristol Heart Inquiry ${ }^{8}$ and was developed to provide a systematic approach to clinical care to ensure consistent high standards and a focus on quality improvement. Clinical governance was initially defined by Scally and Donaldson as:

'A framework through which NHS organizations are accountable for continuously improving the quality of their services and safeguarding high standards of care by creating an environment in which excellence in clinical care will flourish.'
The NHS reform programme have had a significant impact on the delivery of dental care with the introduction of a new General Dental Service contract in 2006, the development of local commissioning and the introduction of clinical governance. Regrettably, the relevance of quality was largely overlooked in the redesign of the new dental contract that had originally been based on NHS dentistry: options for change. ${ }^{10}$

This failure to recognise and incentivise quality has subsequently been recognised as one of the key failings of the new dental contract and highlighted by the Health Select Committee Report on Dentistry ${ }^{11}$ and more recently by Steele in his report on NHS dental services. ${ }^{12}$

The continued drive to improve the qualities in the delivery of healthcare was a key focus of the Darzi Report in 2008, High quality care for all, ${ }^{13}$ that stressed quality is considered to be at the centre of the NHS. The vision, which the report described, was of an NHS that gave patients and the public more information and choice, worked in partnership and had quality of care at its heart.

Despite the change of Government in 2010, the importance of quality has been reaffirmed by the new Secretary of State for Health, the Rt Hon. Andrew Lansley ${ }^{14}$ and this emphasis is likely to persist.

To ensure the qualities of care in relation to health, there needs to be clarification of what it means. By defining the term, it 
also allows measurements of quality to be made, permits benchmarking of any findings against a set of agreed standards and the development of a system to monitor and encourage continuous improvement.

\section{WHAT IS QUALITY?}

Deming defined quality as 'surpassing customers' needs and expectations throughout the life of the product.' ${ }^{1}$ Within healthcare the product or outcome can be difficult to ascertain. Quality is therefore considered by some to be an abstract or nebulous entity which does not lend itself to be easily defined or measured. ${ }^{3}$ Sipkoff discussed the difficulties in defining quality when he stated that:

'Quality, like beauty, is in the eye of the beholder. The word is ubiquitous in health care, but what does it mean to health plan leaders, providers, patients, and payers? Is quality a process, a tactic, or just an aspiration?' ${ }^{\prime 15}$

Donabedian ${ }^{16}$ conceded that assessment of quality must rest on a conceptual and operationalised definition but considered that quality could be defined and measured effectively. He recognised that quality was multidimensional and in his seminal text, Evaluating the quality of medical care published in 1966 he describes quality as the product of two factors: the science and technology of healthcare, and the application of that science and technology. ${ }^{17}$ Donabedian defined care of high quality as:

'The kind of care which is expected to maximize an inclusive measure of patient welfare, after one has taken account of the balance of expected gains and losses that attend the process of care in all its parts. ${ }^{17}$

He did, however, recognise that there are different approaches to the definition of quality, which would lead to varying approaches to quality management. Maxwell ${ }^{18}$ developed the multidimensional view further (Table 1), suggesting:

'Six dimensions of quality that need to be recognized separately, each requiring different measures and different assessment skills.'

Donabedian described the attributes of quality along similar lines to that of Maxwell and described seven key areas: efficacy, effectiveness, efficiency, optimality, acceptability, legitimacy and equity. He states that these attributes:

'Taken singly or in a variety of combinations, constitute a definition of quality and, when measured in one way or another will signify its magnitude. ${ }^{\prime 19}$

Campbell et $a l .{ }^{20}$ described a relatively simplistic approach to the definition of quality and believe that two dimensions are of importance: access and effectiveness. They went on to suggest that there were subtle differences between quality of care for the individual and that of a population, and proposed that when looking at populations the additional factors of equity, efficiency and cost need to be considered. This reflects the earlier work of Donabedian ${ }^{21}$ who also described the difference in emphasis of quality between individuals and that within a population.

Campbell et al. ${ }^{20}$ summarised their work to provide a simple definition of quality based on:

'Whether individuals can access the health structures and processes of care which they need and whether the care they received is effective.'

This simplified approach to care, although welcome, does not promote the value of patient-centred care and the importance of this factor in patients' perception of quality is not recognised.

The Institute of Medicine has defined the quality of care as:

'The degree to which health services for individuals and populations increase the likelihood of desired health outcomes and are consistent with current professional knowledge. ${ }^{22}$

More recently the organisation has provided more detail to support their definition by outlining the components of quality care based on a conceptual approach. Quality care should be: safe, effective, patient centred, timely, efficient, and equitable. ${ }^{23}$

At the same time the Department of Health published its White paper that defined quality in the NHS in terms of patient safety, clinical effectiveness and the experience of patients. ${ }^{23}$ These key factors laid the foundations for the quality indicators which were subsequently proposed in Measuring for quality improvement. ${ }^{24}$
Table 1 Dimensions of healthcare quality

\begin{tabular}{l}
\hline Access to services \\
\hline Relevance to need \\
\hline Effectiveness \\
\hline Equity \\
\hline Social acceptability \\
\hline Efficiency and economy \\
\hline
\end{tabular}

In looking at the various definitions of quality it is apparent that although there may be differing opinions, there is a consensus that it is multidimensional and the important factors are patient safety, access, clinical effectiveness and patient experience. It is also evident that there are distinct differences between the individual and a population, and any assessment of quality must reflect this.

\section{HOW DO WE ASSESS QUALITY?}

It is important to be able to measure quality and benchmark against a set of agreed standards. If this is not possible, it is impossible to assess whether care is of the appropriate qualities, or indeed whether it is improving. As Darzi wrote:

'We can only be sure to improve what we can actually measure. ${ }^{13}$

How we measure quality has been considered by many, and Donabedian is widely recognised as one of the most important influences in developing evaluation of quality in healthcare. He introduced the concept of structure, process and outcome as the basis for evaluating quality and other work in this area has stemmed from this landmark paper. ${ }^{17}$

Quality indicators can be related to structure, process, or outcome of healthcare with each having their own uses and limitations. Structure relates to the setting or system in which care is provided and would include the facilities, equipment, staffing, and the organisation as a whole. Process relates to the delivery of care and the implementation of treatment by the provider. Outcome is a measure or reflection of the results of the care or treatment that was undertaken.

The structure of an organisation can have a profound influence on the quality of care provided but has a rather weak relationship to corresponding variation 
in quality. ${ }^{19}$ The advantages as detailed by Donabedian are that structures do tend to be stable, readily observable and easily documented.

Measures of process and outcome would appear to offer a more reliable approach to quality assessment and are therefore predominately favoured by those involved in managing quality. Process measures are widely used and assess:

'What the provider did for the patient and how well it was done.'25

Such measures are often easily recorded and offer a strong indication of the success or failure of that process in achieving the desired outcome. Process measures can also demonstrate the success or failure of a given process and provide the clinician with the opportunity to develop a quality improvement programme. However, for process measures to be effective they need to be validated against a specific outcome and ideally have a strong evidence base in support of that relationship. Unfortunately there is only limited evidence currently underpinning many of the procedures, techniques and processes being currently used, although this is gradually being addressed through the work of various bodies including the Cochrane Collaboration, the Centre for Reviews and Dissemination, and the National Institute for Health and Clinical Excellence.

In recent years there has been a strong desire to use outcome measures as the preferred indicator of quality, and many contractors favour the use of this approach to assess clinical effectiveness. Indeed, Davies and Crombie argue that:

'These measures have an intuitive appeal: high quality care should be reflected by good outcomes. ${ }^{26}$

This approach is reiterated within the Darzi Report ${ }^{13}$ that argues for the benefits of measuring outcomes and the new Government has recently confirmed that they will continue to pursue this approach. ${ }^{14}$

\section{THE APPLICATION OF QUALITY INDICATORS IN PRIMARY CARE}

The Department of Health's vision to address shortfalls in the delivery arrangements of NHS dental care currently remain influenced by The Steele Report. ${ }^{12}$ The work argues strongly for the development of a dental contract that uses measures of outcome and not activity. Indeed, the use of the Personal Dental Services Plus (Warburton) contracts to address perceived access problems has seen the adoption of key performance indicators (KPIs), although the majority of them have dealt with performance as opposed to outcome measures. This move towards payment for performance is highly likely to feature in any changes that are implemented in the future.

However, such moves are not without their problems. Outcome measures have a number of weakness including interpretation, "the problem of attribution' 19 and contemporaneity. Concerns have also been raised concerning the sidelining of process in favour of outcomes as an indicator of quality ${ }^{25-27}$ and if clinicians are to see pay related to quality performance will need to recognise where exactly they can exert control. It would be totally inappropriate to link any reward arrangement to factors that a contract holder has no responsibility over.

The issue of incentivising quality improvements in care has been attempted in primary care for general medical practitioners. In 2004 a new General Medical Services Contract was introduced to enhance patient care and improve the working conditions of contract holders. The contract included a pay-for-performance component with financial incentives attached to delivery of agreed quality measures. Several studies have shown that financial incentives can result in improvements in quality, ${ }^{28,29}$ although in a recent review of the literature Peckham and Wallace state that:

'The evidence on the effect of P4P on quality is limited. ${ }^{30}$

The scheme, known as the Quality and Outcomes Framework (QOF) ${ }^{34}$ has been developed to reward quality of care rather than simply dealing with numbers of patients registered. Initially 136 indicators were introduced which were divided into the following four domains:

- Chronic disease management

- Practice organisation

- Patient experience

- Additional services.
The measures were weighted and a maximum score of 1,050 points was achievable. This potentially provided an additional 25 to $30 \%$ funding for the practice and was backed by an investment of an additional $£ 1$ billion annually. There was strong support from the profession for the introduction of QOF and 99.6\% of practices choose to participate in this voluntary scheme.

As with any investment on such a scale, the hope was that significant benefits would have been realised. This would appear to be the case from the GPs' perspective. There were considerable financial rewards for embracing the contract changes and improvements in their working conditions has also been reported..$^{32}$

Furthermore, Walley et al. ${ }^{32}$ also found that despite initial reservations by GPs regarding loss of autonomy and increased workload, they actually found that there was increased job satisfaction and that work pressure had declined. There were also perceived gains in prevention and chronic disease management that exceeded their expectations. While the implementation of QOF appears to have been successful from the providers' perspective, there is some concern that this has not necessarily been translated into improved quality of care for patients.

Campbell et $a ._{.}{ }^{28}$ looked at the effect of pay for performance on quality within primary care using quality indicators for three chronic illnesses: asthma, diabetes and heart disease. While the authors found an increased rate of improvement in two of the three conditions, once the targets had been reached there was a slowing down and in two cases a decline.

Lester et al..$^{33}$ investigated the impact of removing indicators from a $\mathrm{P} 4 \mathrm{P}$ scheme for screening for cervical cancer and diabetic retinopathy in California. They found that a decrease in performance occurred following removal of the financial incentives that indirectly supports the work of both Campbell ${ }^{28}$ and Rosenthal. ${ }^{29}$

In an editorial review Mangin and Toop were heavily critical of the new contract and their colleagues, stating that:

'General Practice has accepted an initially very well paid, but disempowering, system of micromanagement, characterised by an increasing focus on a small number of measurable yet relatively meaningless indicators. ${ }^{34}$ 
Considerable research is being undertaken to assess the impact of QOF and time will tell whether this has ultimately been a worthwhile and cost-effective approach to quality patient care or not.

\section{QUALITY INDICATORS IN DENTISTRY}

In 2006 a new dental contract was introduced which was loosely based on Options for change. ${ }^{10}$ The contract was introduced to improve patient access, promote prevention, stop the 'dental treadmill' and deliver quality. Unfortunately these laudable aims were never realised and the focus remained on quantity not quality with the Unit of Dental Activity (UDA) in England being used as the currency linking contractors and commissioners.

The profession was highly critical of the introduction of (UDAs) and the resultant focus on targets, with little if any recognition of the quality of the service provided. ${ }^{35}$ The attraction of the GP style QOF was apparent and viewed as a possible way of addressing some of the failings of the dental contract by providing a focus on quality care.

There is limited research available into the impact of pay-for-performance to promote delivery of quality within dentistry, although there were data derived through the former contract demonstrating a relationship between prescribing patterns and changes in reimbursement. In a remarkably short sighted move, the Department of Health threw away the single most important arrangement for helping measure and hence improve the qualities of care in England with the changes at the former Dental Practice Board. Indeed, current developments suggest that this lesson has not been learnt with the announcement that the Dental Reference Service will also see major alterations in its role.

Not all of the four territories making up the British NHS have followed this path. Indeed arrangements in Scotland have allowed Clarkson et al. to investigate the impact of education and financial incentive against a control in a study of fissure sealant application in children. They demonstrated a 9.8\% increase in compliance with fissure sealant placement when a financial incentive was given and concluded that 'fee-only' was the most cost-effective intervention.
Some of the shortcomings of the new dental contract are being addressed with development of 'blended contracts'. These are agreements in which the overall remuneration is linked to various contractual elements, including activity, capitation and quality. In 2009 the Clinical Effectiveness and Outcomes Group (CEOG) was established to look at quality measures within dentistry. Quality indicators are being developed to look at structure, process and outcome, with the latter demanding the greatest focus.

As previously detailed there can be inherent flaws in over reliance on outcomes and this is particularly true in dentistry where the impact of patient compliance cannot be underestimated. General medical practitioners using the new GMS are affected by the 'inverse care law' identified by Tudor-Hart; ${ }^{36}$ dental practices operating within similar communities are also likely to be affected. ${ }^{37}$ This will unfortunately compound the unfairness and inequity of the UDA arrangements for patients with high needs if it is to feature in any new contract unless significant changes are also made to the present banding system.

When the new GMS contract was introduced significant investment was made available to implement the new scheme with delivery of QOF attracting additional funding. In the current financial climate extra funding is not going to be made available: any quality improvements will almost certainly have to happen within the existing funding constraints.

Quality indicators are most effective when they are used to drive improvements in the quality of patient care and not as a tool to judge performance. The initial experience of quality indicators within NHS dentistry has not been a good one. The Dental Access Contract (PDS Plus or Warburton contract) appears to be predominately focused on performance, efficiency and fiscality, rather than acting as a driver for improved patient care. For quality indicators to be effective in dentistry there needs to be recognition that the things that can be counted do not always count and the things that do count can't always be counted. Quality indicators are destined to play an important role in the future of NHS dentistry and the profession must embrace these changes if they wish to deliver safe, effective, patient-centred care. Politicians, commissioners and providers have a common purpose to provide high quality healthcare within any healthcare system, but unless the participants work together in partnership this will prove to be an unattainable aspiration. There will be a continual chasing of targets and tick boxes rather than a focus on the needs of patients.

Dentistry in the UK, in particular in England, is on the brink of another seismic change in the way in which it is commissioned and funded. One hopes that, finally, quality will be at the heart of this process as was first envisaged in $1997 .{ }^{3}$ As Maxwell stated:

'Quality is not achieved by inspection at the end of the production line nor can it be imposed from above. It is (a) result of the shared aspirations and concerted efforts of all those involved, for whom it is a higher priority than any personal interest. ${ }^{38}$

1. Edwards D W. Out of the crisis. Cambridge, MA: Massachusetts of Technology, 1986.

2. Spicer R. Targets harm patients and are destroying the English NHS. Int J Clin Pract 2009; 63: 1278-1281.

3. Department of Health. The new NHS: modern, dependable. London: The Stationery Office, 1997.

4. Department of Health. Commissioning a patient-led NHS. London: The Stationery Office, 2005.

5. Department of Health. Our health, our care, our say: a new direction for community services. London: The Stationery Office, 2006.

6. World Class Commissioning Programme, Department of Health. (http //www.dh.gov.uk/ en/Managingyourorganization/Commissioning/ Worldclasscommissioning/DH_083204).

7. Department of Health. A first class service quality in the new NHS. London: The Stationery Office, 1998.

8. The Bristol Royal Infirmary Inquiry. Learning from Bristol: The report of the public inquiry into children's heart surgery at the Bristol Royal Infirmary 1984-1995. Cm 5207. London: The Stationery Office, 2001

9. Scally $G$, Donaldson L J. The NHS's 50 anniverary. Clinical governance and the drive for quality improvement in the new NHS in England. BMJ 1998; 317: 61-65.

10. Department of Health. NHS dentistry: options for change. London: The Stationery Office, 2002.

11. House of Commons Health Committee. Dental Services Fifth Report of Session 2007-08. London: The Stationery Office, 2008.

12. NHS Dental Services in England. An Independent Review led by Professor Jimmy Steele. London: Department of Health, 2009.

13. Professor the Lord Darzi of Denham KBE. High quality care for all. NHS next stage review final report. London: The Stationery Office, 2008.

14. Speech by the Rt Hon Andrew Lansley CBE MP, Secretary of State for Health; 'My ambition for patient-centred care' (Available at: http://www. dh.gov.uk/en/MediaCentre/Speeches/DH_116643).

15. Sipkoff M. The new consensus favouring IOM's definition of quality. Manag Care 2004; 13: 18-21, 26-27.

16. Donabedian A. The quality of care: how can it be assessed? JAMA 1988; 260: 1743-1748.

17. Donabedian A. Evaluating the quality of medical care. Millbank Memorial Fund Quarterly 1966; 
44: 166-206.

18. Maxwell R J. Quality assessment in health. Br Med J (Clin Res Ed) 1984; 288: 1470-1472.

19. Donabedian A. An introduction to quality assurance in health care. Oxford: Oxford University Press, 2003.

20. Campbell S M, Roland M O, Buetow S A. Defining quality of care. Soc Sci Med 2000; 51: 1611-1625.

21. Donabedian A. Explorations in quality assessment and monitoring. Vol. 1. The definition of quality and approaches to its assessment. Ann Arbor, Mich: Health Administration Press, 1980.

22. Lohr K. Committee to Design a Strategy for Quality Review and Assurance. In Medicare (ed) Medicare: a strategy for quality assurance. Vol. 1. Washington, DC: National Academy Press, 1990.

23. Committee on the Quality of Health Care in America. Crossing the quality chasm: a new health system for the 21st century. Washington, DC: National Academy Press, 2001.

24. Information Centre. High quality care for all. Measuring for quality improvement: the approach. 2009. (Available at: www.ic.nhs.uk) webfiles/Work\%20with\%20us/consultations/COI/ MeasuringForQualitylmprovement\%20_2 .pdf).

25. Mainz J. Defining and classifying clinical indicators for quality improvement. Int J Qual Health Care 2003; 15: 523-530.

26. Davies H T, Crombie I K. Assessing the quality of care. BMJ 1995; $311: 766$

27. Rubin H R, Pronovost P, Diette G B. The advantages and disadvantages of process-based measures of health care quality. Int J Qual Health Care 2001; 13: 469-474.

28. Campbell S M, Reeves D, Kontopantelis E, Sibbald $B$, Roland M. Effects of pay for performance on the quality of primary care in England. $N$ Engl J Med 2009; 361: 368-378.

29. Rosenthal M B, Frank R G, Li Z, Epstein A M. Early experience with pay-for-performance: from concept to practice. JAMA 2005; 294: 1788-1793.

30. Peckham S, Wallace A. Pay for performance schemes in primary care: what have we learnt? Qual Prim Care 2010; 18: 111-116.

31. Campbell S M, McDonald R, Lester $H$. The experience of pay for performance in English family practice: a qualitative study. Ann Fam Med 2008; 6: 228-234.

32. Whalley $D$, Gravelle $H$, Sibbald B. Effect of the new contract on GPs' working lives and perceptions of quality of care: a longitudinal survey. Br J Gen Pract 2008; 58: 8-14.
33. Lester H, Schmittdiel J, Selby J et al. The impact of removing financial incentives from clinical quality indicators: Iongitudinal analysis of four Kaiser Permanente indicators. BMJ 2010; 340: c1898.

34. Mangin D, Toop L. The Quality and Outcomes Framework: what have you done to yourselves? BrJ Gen Pract 2007: 57: 435-437.

35. Clarkson J E, Turner S, Grimshaw J M et al. Changing clinicians' behaviour: a randomized controlled trial of fees and education. J Dent Res 2008; 87: 640-644.

36. Hart J T. The inverse care law. Lancet 1971; 1: 405-412.

37. Ashworth $M$, Armstrong D. The relationship between general practice characteristics and quality of care: a national survey of quality indicators used in the UK Quality and Outcomes Framework, 2004-5. BMC Fam Pract 2006; 7: 68.

38. Maxwell R J. Dimensions of quality revisited: from thought to action. Qual Health Care 1992; 1: 171-177.

39. Chestnutt I G, Davies L, Thomas D R. Practitioners' perspectives and experiences of the new National Health Service dental contract. Br Dent J 2009; 206: 476-477.

\section{Corrigendum}

\section{General article (BDJ 2011; 210: 431-438):}

'Education, regulation, representation and remuneration in dentistry - who does what?'

In the above general article, the job titles given in the author biography for authors Tom Pepper and Nigel Fisher were incorrect. Tom Pepper is a medical student and Nigel Fisher is a Consultant in Restorative Dentistry, not the other way round. 